\title{
Assédio moral e a violência inata: Contribuições freudianas aos estudos das organizações
}

\author{
Moral harassment and Innate violence: Freud's contributions to organizations studies
}

Amon Narciso de Barros ${ }^{[a]}$, Carolina Riente de Andrade $e^{[b]}$

\footnotetext{
${ }^{[a]}$ Doutor pelo Centro de Pós-Graduação e Pesquisa em Administração (Cepead) da Universidade Federal de Minas Gerais (UFMG), Belo Horizonte, MG - Brasil, e-mail: amonbarros@gmail.com

${ }^{[b]}$ Doutora pelo Centro de Pós-Graduação e Pesquisa em Administração (Cepead) da Universidade Federal de Minas Gerais (UFMG), Belo Horizonte, MG - Brasil, e-mail: carol@tectran.com.br
}

Recebido: 01/05/2011 Received: 05/01/2011

Aprovado: $15 / 12 / 2011$ Approved: 12/15/2011

\section{Resumo}

O presente ensaio teórico pretende contribuir com a reflexão sobre o assédio moral nas organizações produtivas, compreendendo-o como uma questão estrutural das relações de trabalho. Defende-se aqui que a violência no trabalho é fruto de afinidades eletivas entre a conjuntura específica da sociedade contemporânea e as demandas pulsionais dos sujeitos, vinculadas à pulsão de morte, que encontram vazão em demandas da vida hodierna, principalmente, na busca constante pela melhoria da performance. Assim, buscar-se-á discorrer sobre a violência inata dos seres humanos, postulada por Freud em vários de seus textos, objetivando apontar para outras possibilidades de interpretação do fenômeno. Como considerações finais, defende-se que apenas quando o indivíduo tiver possibilidades de sublimação real em seu trabalho e em seus momentos de lazer é que será possível escapar, não completamente, contudo, dos efeitos negativos da pulsão de destruição no ambiente de trabalho.

Palavras-chave: Assédio moral. Psicanálise. Violência.

\begin{abstract}
This theoretical paper aims to contribute to the discussion on bullying in productive organizations, understanding it as a structural issue of labor relations. It is argued that workplace violence is the result of elective affinities between the specific situation of contemporary society and the pulsional demands of the subject, linked to the death drive, which are in flow demands of modern life, especially in the constant search for performance improvement. Thus, this paper will seek to discuss the humans inherent violence, postulated by Freud in several of his texts, aiming point another possibility of the phenomenon interpretation. In the conclusions it is argued that only when the individual has real possibilities of sublimation in their work and in their leisure time the subject can escape, not entirely, from the negative effects of destruction 'instinct' in the workplace.
\end{abstract}

Keywords: Bullying. Psychoanalysis. Violence. 


\section{Introduç̃̃o}

0 presente artigo pretende contribuir com a reflexão sobre o assédio moral nas organizações produtivas, compreendendo-o não apenas como um problema dos indivíduos, mas como uma questão estrutural das relações de trabalho. Buscar-se-á ampliar as interfaces dos estudos organizacionais com a psicanálise, discorrendo sobre a violência inata dos seres humanos, postulada por Freud em vários de seus textos, principalmente após Além do Princípio do Prazer (1920, 1976a). A isso, deseja-se articular reflexões do presente contexto social no qual há permissividade para a agressividade no ambiente de trabalho; pretende-se também aventar a suposição de que apenas numa sociedade com possibilidades de real sublimação ${ }^{1}$ - diferente da sublimação repressiva apontada por Marcuse (1978) e que deixa uma quantidade de energia aprisionada na psique - é que se poderia reduzir drasticamente a violência do homem contra seu semelhante.

Defende-se no presente artigo, portanto, que o problema do assédio moral e da violência em geral no ambiente de trabalho, antes de ser monocausal, é fruto de afinidades eletivas entre a conjuntura específica da sociedade contemporânea e as demandas pulsionais dos sujeitos; estas, vinculadas à pulsão de morte, encontram vazão em demandas da vida hodierna, principalmente, na busca constante pela melhoria da performance.

Diversos autores (p. ex., Freitas, Heloani \& Barreto, 2008) apontam que novas configurações nas relações de trabalho alteram a relação com a estrutura social, provocando sensível ampliação da produtividade sem que se observe, contudo, o aumento de oportunidades de trabalho ou melhoras significativas para os trabalhadores. $\mathrm{O}$ aumento da competitividade, a precariedade e a "precarização" dos empregos, a busca constante pela redução dos custos de produção, a sobrecarga e o desgaste dos trabalhadores são uma realidade no atual cenário organizacional.

Ademais, Corrêa e Carrieri (2004) apontam que as humilhações no trabalho mirando a produtividade dos trabalhadores sempre existiram. Desde a Antiguidade, passando pela escravidão até aos dias atuais, pode-se atestar a violência como forma de se ampliar o rendimento dos trabalhadores. "A agressão física desapareceu com os anos, mas surgiu uma forma mais sutil de atingir o bem-estar do trabalhador: o assédio moral" (Corrêa \& Carrieri, 2004, p. 1066).

Assim, sustenta-se que as práticas de violência no ambiente de trabalho são combatidas de maneira paliativa se os apelos para a mudança se situarem apenas no âmbito da legislação ou dos chamamentos à moralidade. A solução para esse problema poderia se situar, portanto, na alternativa de se abrir aos sujeitos possibilidades de sublimação livre em seu trabalho e em outros ambientes de sua vida. Contudo, no atual modelo capitalista, essa proposta parece pouco viável.

Para atender ao que se propõe, o presente artigo está dividido em cinco seções. Na sequência, são apresentadas algumas considerações relevantes acerca do assédio moral e, posteriormente, são abordados pontos da teoria psicanalítica que sustentam a posição adotada. Finalmente, há uma revisão acerca do contexto social e suas implicações sobre o trabalho.

\section{Contextualizando o assédio moral: Violência silenciosa no trabalho}

Ao desenvolver uma pesquisa com vítimas de bullying ${ }^{2}$, Tracy, Lutgen-Sandvik e Alberts (2006) levantam as metáforas utilizadas pelos sujeitos para representar o que sentiam quando se viam submetidos a práticas de abuso perpetradas por colegas. Os autores apontam que as vítimas das agressões encontraram dificuldades para descrever o que haviam passado. Para conseguir se expressar, muitos dos sujeitos entrevistados recorreram a metáforas, que são imagens representativas com valor simbólico. Contudo, é interessante apontar que na ótica de Freud (1976g) esta é uma maneira imprecisa de se trazer as sensações reais do inconsciente ao consciente. A tortura foi nesse estudo, uma imagem bastante utilizada para ilustrar o que as pessoas sentiam. A dificuldade percebida de expressar o que haviam passado coaduna com o caráter fugidio da pulsão de morte, que se expressa, muitas vezes,

\footnotetext{
1 Diz-se que a pulsão é sublimada na medida em que é derivada para um novo objetivo não sexual e em que visa objetos socialmente valorizados" (Laplanche \& Pontalis, 2001, p.495).

2 Termo em inglês que equivale a "assédio moral".
} 
de maneira implícita, além de trazer à tona o quão naturalizadas são as práticas de violência presentes no cotidiano que, em grande parte das vezes, só são percebidas pelos sujeitos quando efetivadas reiteradamente.

Talvez, justamente pela prática não ser sempre clara e ser de difícil apreensão, a reflexão e o debate sobre o assédio moral são relativamente recentes no Brasil. Aparentemente as discussões ganharam expressividade no meio acadêmico, inicialmente com a dissertação de Barreto (2000) e com as contribuições de Freitas (2001), especialmente ao apresentar a obra de Hirigoyen (2000) lançada originalmente na França. Atualmente, o tema tem presença na mídia e é discutido, em particular, pelo movimento sindical e no âmbito do legislativo, porém ainda sem legislação específica para o assunto (Brasil, 2002).

Contudo, nas empresas ainda parece ser um assunto velado. Freitas, Heloani e Barreto (2008, p. 16) apontam para o fato de que "a violência expressa no ambiente de trabalho contemporâneo pode ser uma manifestação de uma violência maior que encontra seus fundamentos ... em uma organização do trabalho cada vez mais sem compromisso com o ser humano". Para os autores, "trata-se, portanto, de uma violência assumida como um efeito colateral simplesmente, ou seja, uma violência que se quer naturalizada" (Freitas, Heloani \& Barreto, 2008, p. 16). Sustenta-se aqui que ela existe em decorrência da própria organização capitalista da produção e que impede a plena satisfação dos sujeitos.

Assim, ressalta-se o entendimento de Dejours (1991), que afirma que as questões do desejo e de sua satisfação são parte do trabalho, o que fomenta a ideia de que as pessoas são, em parte, aquilo que fazem e o trabalho que executam. Para o autor, cada vez que leva a cabo a resolução de problemas que lhe são colocados e que obtém o reconhecimento social de seu trabalho, o sujeito recebe também reconhecimento subjetivo. Por outro lado, deve-se colocar em relevo que esse reconhecimento também pode advir de comportamentos que, apesar de naturalizados, permitem ações agressivas ou violentas e que não são saudáveis para o sujeito ou para seus pares.
Autores como Enriquez (1997) e Freitas (1999) reforçam que o atual sistema com o qual lida a sociedade manipula as armadilhas do desejo do indivíduo; e "nele, o sentimento de potência o torna impotente, pois a imagem de expansão ilimitada não é outra senão a ilusão de uma projeção sem limites, que a empresa cultiva de si e a repassa por meio de sua cultura" (Freitas, Heloani \& Barreto 2008, p. 11). Esse ambiente é que impõe grandes demandas aos trabalhadores e propiciam o surgimento do assédio moral, pois naturalizam a violência pelo pretexto da produtividade.

Hirigoyen (2002) afirma que o que é novo em relação ao assédio moral são a intensificação, a gravidade, a amplitude e a banalização do fenômeno. A autora ressalta ainda a abordagem que tenta estabelecer o nexo-causal com a organização do trabalho e tratá-lo como não inerente às atividades que o sujeito desempenha, mas relativo às condições em que este é realizado. Entretanto, entende-se que o que a autora aponta como novidade é característica - embora não necessária ou constante - no processo de produção capitalista. É claro que não é o trabalho em si — tomado em sentido amplo - que propicia o assédio moral e que o estabelecimento de relações de causa e efeito não reducionistas (i.e., que não se focam apenas na particularidade do caso específico) poderia contribuir para a solução do problema, que passaria por uma ampla transformação da sociedade.

Hirigoyen (2002) não diverge dos apontamentos de Corrêa e Carrieri (2004), que afirmam que apesar do termo "assédio moral" ser relativamente novo, ele expressa um fenômeno tão antigo quanto o próprio trabalho. Nesse sentido, é que se coloca em questão a relevância dada ao tema no presente momento. Se os trabalhadores sempre tiveram que conviver com violências diversas, pois necessitam de vender sua força de trabalho para conseguir o seu sustento, seria efetivo tentar sanar esses problemas localmente, colocando a culpa da prática de abusos unicamente na forma como cada organização específica se estrutura? Vale ressaltar que, algumas condutas violentas presentes no ambiente organizacional são frequentemente confundidas com assédio moral ${ }^{3}$. Entretanto, Hirigoyen (2002) aponta que o assédio se caracteriza por ações frequentes

3 Essa conceituação trazida por quase todos os atores que adotam o tema é que cria a necessidade de se separar a discussão entre violência e assédio moral. Entretanto, apesar de se considerar importante rever esse posicionamento da autora, acredita-se que seria necessário um trabalho específico para fazê-lo. Para uma discussão sobre o assunto, ver Bicalho (2009), que aponta, dentre outras questões, que a recursividade não necessariamente serve de critério para definir o quanto o sujeito foi ou não vítima de assédio. 
e deliberadas, sendo definido pela autora como "qualquer conduta abusiva (gesto, palavra, comportamento, atitude...) que atente, por sua repetição ou sistematização, contra a dignidade ou integridade psíquica ou física de uma pessoa, ameaçando seu emprego ou degradando o clima de trabalho" (Hirigoyen, 2002, p. 17).

Ainda segundo Hirigoyen (2002, p. 67), a intenção consciente é agravante da agressão moral na qual "a perversidade não provém de um problema psiquiátrico, mas de uma racionalidade fria combinada a uma incapacidade de considerar os outros como seres humanos" (Hirigoyen, 2000, p. 13). Sabe-se que não se pode exigir da autora o uso de outros referentes que não os dela. Mas entende-se que os aportes freudianos, desde seu ceticismo em face da racionalidade onipresente (a terceira ferida narcísica ${ }^{4}$ apontada pelo autor) até sua postulação das pulsões de vida e de morte, podem enriquecer a discussão sobre a temática. Diante disso, algumas contribuições da psicanálise freudiana serão apresentadas a seguir, possibilitando a compreensão do tema sob uma nova abordagem, em relação àquela mais frequente na literatura que trata do assunto.

\section{Alguns aportes psicanalíticos para compreensão da questão da violência}

Freud coloca aos estudos sobre a violência no local de trabalho (dentre eles os estudos sobre o assédio moral) uma questão fundamental: a pulsão de morte (e sua equivalente direcionada ao ambiente externo, a pulsão de destruição). Para esse pensador, a violência é atributo incontornável dos seres humanos. Isso porque haverá sempre um quantum de energia psíquica destrutiva que deve ser direcionado ao ego ou a objetos externos. Desse modo, no atual contexto social, chamamentos à moral ou ao aprimoramento das leis parecem meros paliativos na resolução desse problema. Como apontam Jorge e Bastos (2009, p. 23):

ainda que Freud ressalte o trabalho como fonte de satisfação quando livremente escolhido a partir das inclinações do sujeito, ele sublinha igualmente que, em geral, o trabalho não é prezado pelos homens e não se configura como uma fonte de satisfação tão prazerosa quanto outras [grifo meu].

É o próprio Freud (1976d) quem salienta que o trabalho que é selecionado de acordo com a vontade do indivíduo é que pode possibilitar a sublimação. Entretanto, no atual modelo de sociedade, poucos ou mesmo pouquíssimos - têm a oportunidade de fazerem o que querem. Ademais, há todo um discurso no qual a organização produtiva capitalista aparece como se fosse corpo unitário e que tem por praxe se mostrar na posição de sujeito e de se apresentar como objeto possível de se inserir no âmbito das relações com os funcionários como digna de afeto (o que é, por vezes, reforçado por suas práticas e normas).

Dado o constante aumento da instabilidade nos empregos, é importante ter em vista que a perda de um objeto no qual havia investimento libidinal, e que era alvo de amor, pode causar problemas graves no funcionamento do aparelho psíquico do sujeito, como o luto e a melancolia (Freud, 1976c). Entretanto, acredita-se que mesmo se deixada de lado a possibilidade de demissão sumária, é possível que a relação de trabalho permeada pelo que é tido como "normalidade" estimule a descarga da agressividade que, para Freud (1976a, 1976d), é inerente ao homem.

$\mathrm{O}$ autor ainda aponta que as ações do homem são regidas por duas forças distintas que servem como vetor para as pulsões e que colocam o sujeito em movimento: Eros e Thanatos ou, a pulsão de vida e a pulsão de morte, respectivamente (Freud, 1976a). Ambas se encontram presentes em maior ou menor quantidade em toda ação e todo investimento psíquico feito pelo sujeito, sendo que, a pulsão de morte, pode se realizar enquanto agressividade contra si ou contra um objeto externo. 0 que se observa é que a presente estrutura socioeconômica historicamente localizada trata com naturalidade a objetivação dos instintos agressivos, perpetrada no ambiente de trabalho, desde que ela permaneça velada e não evolua para a violência física.

Para Sigmund Freud, o ser humano atua sempre com vistas a obter prazer ou fugir do desprazer. É o

\footnotetext{
4 As outras duas foram a descoberta de Galileu, que apontou que a terra não é o centro do universo, e os achados de Darwin, que nos colocam em descendência direta dos primatas, tirando assim a singularidade do homem, enquanto criação divina direta
} 
que o autor chama de "princípio do prazer", o qual consiste na tentativa da psique de manter a quantidade de excitação no menor nível possível; ele é "invariavelmente colocado em movimento por uma tensão desagradável e que toma uma direção tal, que seu resultado final coincide com uma redução dessa tensão, isto é, com uma evitação do desprazer ou uma produção de prazer" (Freud, 1976a, p. 17). Entretanto, o princípio do prazer pode se mostrar perigoso para o sujeito diante das imposições colocadas pelo mundo exterior. Ele é assim substituído pelo princípio da realidade, que "não abandona a intenção de fundamentalmente obter prazer; não obstante, exige e efetua o adiamento da satisfação, o abandono de uma série de possibilidades de obtê-la, e a tolerância temporária do desprazer como uma etapa no longo e indireto caminho para o prazer" (Freud, 1976a, p. 20).

Marcuse (1978) aponta que a razão é fruto do princípio de realidade. Nisso, ele está em consonância com Freud (1976g), que afirma ser esse um atributo do ego que também se forma a partir do princípio de realidade, controlando os impulsos do id. Porém, para Marcuse, o princípio de realidade em nossa sociedade é submetido ao "princípio de desempenho", que demanda maior produtividade dos indivíduos à custa de sua satisfação libidinal:

... o princípio da renúncia produtiva, que se desenvolve como sistema de todas as modificações das pulsões, de todas as renúncias, substituições, sublimações que a sociedade deve impor aos indivíduos para transformá-los, de portadores do princípio do prazer, em instrumentos de trabalho socialmente utilizáveis (Marcuse, 2001, p. 122).

Marcuse (1978) fala ainda de uma "mais-repressão" como sendo o excesso de repressão demandado do sujeito, com vistas apenas a manter o status quo. 0 sistema vigente é sustentado pelas normas e regulamentos sociais inculcados nos sujeitos desde sua mais tenra infância até a passagem pelas diversas instituições sociais que reforçam a ideologia dominante, mantenedora da atual organização da sociedade. Assim, é aberto espaço para que se dê vazão às pulsões sob a regência do poder destrutivo de Thanatos, que são aceitas socialmente, desde que veladas, e o sujeito se vê até mesmo incitado a dar vazão a essa pulsão, por uma via possível, para se extrair maior produtividade do trabalho. 0 homem que se faz necessário à atual forma de organização social é construído com base na repressão aos instintos e na educação propiciada pelas várias instituições sociais (Ruiz, 1998).

Entender que o trabalho executado no interior da maioria das organizações capitalistas é alienado/alienante constitui fator relevante para se compreender a dinâmica da sujeição que existe no interior dessas organizações. Os homens, alheios aos produtos de seu trabalho, veem o dinheiro que recebem como o único fruto de seus esforços e, assim, não reconhecem sua capacidade de transformar a realidade a partir de suas ações e não conseguem sublimar suas pulsões de maneira satisfatória. São instados a medirem-se não pela sua capacidade de transformar a realidade que os cerca, mas a partir da quantificação que torna seu salário mais concreto do que o trabalho que desempenham (Pagés et al., 1987). Dessa maneira, a sublimação que o trabalho poderia proporcionar fica barrada pela impossibilidade de se obter prazer com a atividade desempenhada.

A execução de atividades repetitivas e enfadonhas, características de grande parte do trabalho realizado na atual sociedade, dificulta o investimento de energias psíquicas no desempenho das funções produtivas. Nesse sentido, também a sublimação é ao menos parcialmente impossibilitada, pois para que se desenrolasse a contento seria necessária uma atividade compensadora como via de descarga das pulsões. Essa possibilidade é barrada e o sujeito se vê compelido a satisfazer uma demanda exclusivamente externa, oriunda da organização produtiva na qual está empregado - atividade para a qual é "enformado" pelos vários aparelhos sociais voltados para a "educação do homem".

Assim, há uma parcela de energia psíquica que não pode ser investida no trabalho e permanece no interior da psique do sujeito. Como Freud (1976f) aponta, a pulsão é uma energia de ordem quantitativa. Há um quantum de energia psíquica no interior da psique e que precisa ser descarregada. Ora, se o sujeito reprime essa pulsão, ela deve voltar de alguma maneira, investida em outro objeto, havendo nesse caso o que se pode chamar de deslocamento. Essa pulsão pode também ser sublimada, mas concorda-se com Marcuse (1991) quando ele aponta que na sociedade capitalista essa sublimação se dá como sublimação controlada, institucionalizada, vinculada ao "princípio de desempenho" (Marcuse, 1978). 
A suposição então é que o sujeito, quando reprime uma pulsão e direciona suas energias apenas para fins produtivos, permanece com necessidade de dar vazão a essa energia acumulada e que não foi descarregada de maneira completa. Não podendo direcioná-la para o trabalho, que em geral oferece poucas possibilidades de sublimação livre, os impulsos permanecem no interior da psique, por terem sido sublimados apenas parcialmente. Podem, assim, ser orientados em direção à organização na qual o trabalho é desenvolvido, para os sujeitos com os quais ele é desenvolvido, ou mesmo para o próprio ego (ver, por exemplo, Barros, Riente \& Guimarães, 2008). Marcuse (1978, p. 46) salienta que o "instinto de morte é destrutividade não pelo mero interesse destrutivo, mas pelo alívio de tensão".

É de se notar que muitas vezes o trabalho desempenhado é fonte de desprazer, mas mesmo assim o sujeito permanece exercendo-o. Além da determinação econômica, que os impele ao trabalho, e de uma possível propensão a descarregar parte de suas pulsões na modificação do mundo exterior, é necessário considerar que os sujeitos dispõem de mecanismos de defesa - elencados por Anna Freud (1990) — que os capacita a reprimir pulsões negativas relacionadas, também, ao exercício do trabalho. Entretanto, essa pulsão reprimida não desaparece simplesmente da psique, mas permanece criando tensão enquanto não houver a descarga da energia pulsional. Essa descarga é que pode se tornar manifestação da pulsão de destruição voltada para um objeto externo e fazer com que se estabeleçam reações violentas a esse objeto. 0 assédio moral pode, dessa maneira, ser a expressão da descarga de uma pulsão que não pôde ser direcionada a outros objetos.

A naturalização da violência faz com que as pessoas passem a se submeter e aceitar a sujeição, dado que ela é percebida como parte da natureza das relações sociais, acomodando-se às demandas feitas pelo ordenamento social. Assim, tem-se espaço nas organizações tanto para comportamentos sádicos, quanto para comportamentos masoquistas lembrando que, para Freud (e.g. 1976e), ambas as posturas são indissociáveis, uma vez que o masoquista é, em certo sentido, sádico em relação a si mesmo e que o sádico pode estar extravasando uma punição da qual inconscientemente e originalmente seria ele o alvo.
Uma vez que a competitividade é exacerbada e as exigências colocadas são crescentes, a sublimação parcial - que se dá pela via do trabalho pode se mostrar ineficiente para evitar que parte da agressividade que não foi canalizada produtivamente passe a mirar outros sujeitos na organização ou o próprio ego. No primeiro caso, no qual a agressividade seria destinada a um objeto exterior ao sujeito (o sadismo) ter-se-ia uma relação puramente objetal com o outro, utilizando-se da pessoa como meio tanto para dar vazão à pulsão destrutiva quanto para buscar agradar ao objeto que havia sido colocado no ideal de ego (a organização). No outro caso, a agressividade é direcionada para o próprio ego do sujeito (masoquismo) que é alvo da censura do superego e merece ser punido. Ocorre por exemplo, a identificação de si com um explorador, ou com um incapaz, que não atende às expectativas superegoicas. Deve-se, entretanto, ressaltar que, para Freud (1976a; 1976d; 1976e), a ambivalência está presente em ambos os casos, havendo, na verdade, um predomínio de uma dada forma de expressão da agressividade. Jorge \& Bastos (2009, p. 25) apontam que a necessidade de satisfação da pulsão, ou de gozo,

[é] aquilo que se deve considerar em psicanálise como sendo, propriamente falando, a perversão. Pois a perversão não designa na psicanálise qualquer forma de comportamento sexual considerada hoje como minoria (e outrora, como aberração), mas sim uma determinada posição subjetiva na fantasia que implica em tomar o outro como objeto, na medida em que o perverso só quer do outro aquilo que este pode lhe proporcionar de gozo e satisfação, nada mais.

Como aponta Freud (1976d), a sociedade demanda dos indivíduos uma determinada repressão pulsional de modo a permitir a vida em grupo. Róheim (1972), no mesmo sentido, afirma que a repressão é condição sine qua non para o surgimento da civilização. Talvez um fator contribuinte para que a descarga dessa energia reprimida se dê no ambiente de trabalho, na forma de ações agressivas, sejam as poucas possibilidades para que ocorra a sublimação completa das pulsões somadas à gratificação e encorajamento recebidos por aqueles que direcionam essa energia para o incremento da produtividade. Marcuse (1978) e mesmo Freud (1976c) atestam que a superação da escassez de produtos, que é crônica na sociedade, talvez 
possibilitasse que os sujeitos fizessem investimentos pulsionais em outros espaços de vida de forma mais saudável, sem que Thanatos se manifestasse como pulsão de destruição.

Convém ainda salientar que Freud (1976b, p. 257) afirma que se a força do ego diminui, "quer pela doença, quer pela exaustão", pode haver um desequilíbrio em relação à satisfação dos instintos por vias "anormais". O autor aponta que esta é "uma justificação do direito à importância etiológica de fatores não específicos, tais como o trabalho excessivo, o choque etc." (p. 258, em nota, grifos ausentes no original). É interessante notar que para Jorge e Bastos (2009, p. 28) o trabalhador é privado até mesmo de sua posição de satisfação masoquista, pois

Ele é um objeto que produz objetos de gozo para um senhor que desfruta desse gozo e com o qual ele não tem o menor contato - e muitas vezes nem mesmo o conhece. Assim, o trabalhador é duplamente privado, pois não goza dos objetos que produz, nem de sua posição masoquista de objeto, pois ele não mais é um objeto de gozo, mas, sim, um objeto produtor de objetos de gozo.

Sacrifícios são aceitos para que a ordem estabelecida se mantenha, mas é ela própria que demanda esses sacrifícios periódicos. Os sujeitos acabam aceitando injustiças para que possam permanecer inseridos na organização, pela via do trabalho e, dessa maneira, manter sua colocação na sociedade e, em muitos casos, garantir seu sustento e sua sobrevivência. Muitos aceitam ver os pares perdendo o meio de vida e se submetem a cargas extenuantes de esforço físico e psíquico para se manterem no mesmo lugar. Ao mesmo tempo, grande parte das vezes, o máximo que podem almejar é ocupar o lugar de agente opressor. Essa prática, que visa manter, na maioria das vezes, lucros crescentes, não deveria ter lugar numa sociedade em que a abundância obtida por elas é desfrutada apenas por poucos. Apontam Adorno e Horkheimer (1985, p. 54) que

Quem pratica a renúncia dá mais de sua vida do que lhe é restituído, mais do que a vida que ele defende. Isso fica evidente no contexto da falsa sociedade. Nela cada um é demais e se vê logrado. Mas é por uma necessidade social que quem quer que se furte à troca universal, desigual e injusta, que não renuncie, mas agarre imediatamente o todo inteiro, por isso mesmo há de perder tudo, até mesmo o resto miserável que a auto-conservação lhe concede. Todos esses sacrifícios supérfluos são necessários: contra o sacrifício.

Tudo no cenário organizacional aponta para a necessidade de mostrar que as pressões subjetivas e sociais aos quais os sujeitos são submetidos os levam a uma desordem nos seus investimentos pulsionais. Concorda-se aqui com Adorno e Horkheimer (1985, p. 140) quando afirmam que "é a ordem que não pode sobreviver sem a desfiguração dos homens". Assim, muitas das violências observáveis no ambiente de trabalho são frutos dessa "desfiguração" pela qual passa o sujeito para se submeter aos desígnios da ordem hegemônica. Como aponta Lukács (2003, p. 211):

Do mesmo modo que o sistema capitalista produz e reproduz a si mesmo econômica e incessantemente num nível mais elevado, a estrutura de reificação, no curso do desenvolvimento capitalista, penetra na consciência dos homens de maneira cada vez mais profunda, fatal e definitiva.

Assim, entende-se que tratar outros sujeitos como objeto, para além de ser uma "anomalia", um comportamento altamente desviante, é algo que se inscreve cada vez mais profundamente na configuração da presente sociedade. Nesse cenário emergem o contexto de competitividade crescente e o paulatino abandono da razão substantiva - calcada em conceitos e em critérios objetivos de verdade, mesmo que para valores morais - em favor da subjetiva que enfatiza o cálculo e a adequação entre meios e fins (Horkheimer, 2002); esses dois fatores contribuem para que sejam naturalizados comportamentos que, apesar de contribuírem com a produtividade das empresas, degradam as possibilidades de os sujeitos exercerem livremente suas capacidades.

\section{Contexto social: do investimento pulsional ao assédio moral}

As organizações capitalistas reificadas e tomadas como sujeito não "se propõem" a "amar" igualmente a todos os membros do grupo, mas somente aqueles que merecem. Nesse sentido, é interessante observar que: "É o amor equânime do líder em 
relação a cada membro que corrobora para os impulsos cruéis e hostis não recaírem sobre os componentes do grupo, mas sobre aqueles que estão fora dele" (Nakasu, 2005, p. 4). Assim, quando a empresa reificada coloca seu "amor" com a condicional do desempenho, abre espaço para que comportamentos violentos se manifestem dentro do grupo.

Entende-se, por exemplo, que quando se busca construir ambientes nos quais é demandado um funcionário cada vez mais competitivo e que recebe promessas de reconhecimento sempre que se doar mais se exacerba as tensões do aparelho psíquico desse sujeito. Isso, além de contribuir para o desempenho da organização, pode aumentar a possibilidade de as pulsões agressivas dos sujeitos serem direcionadas para os outros membros do grupo: "Quando o laço afetivo entre os membros e o líder sofre algum abalo o equilíbrio se desfaz: o ego é investido narcisicamente e a destrutividade se volta diretamente contra os colegas e contra o líder" (Nakasu, 2005, p. 2-3). Assim, o sujeito pode direcionar para os colegas uma agressividade que originalmente teria como alvo a própria empresa ou, numa acepção mais próxima da letra freudiana, a sociedade.

Os sujeitos habitam num mundo cada vez menos aberto a possibilidades de sublimação livre de controles e formatações alheias, que permitam a liberação saudável de suas pulsões agressivas, como já apontava Marcuse (1955/1978; 1964/1991). Ao mesmo tempo, o trabalho alienado e sem sentido não se mostra capaz de canalizar as pulsões dos sujeitos e passa a ser analisado, primordialmente, a partir do retorno financeiro que ele propicia. 0 ser humano é, por vezes, computado apenas enquanto força de trabalho à disposição do mercado. A capacidade que lhe é inerente, de modificar o ambiente natural por meio de sua ação sobre o mundo, deixa de ser característica do sujeito específico e passa a ser atributo da "humanidade em geral", dissolvendo assim os atributos que são também individuais na coletividade/sociedade.

Parece que a sociedade funciona como uma engrenagem que entrega produtos, mesmo após o declarado "fim do trabalho" ou do advento do "trabalho imaterial", no sentido do que Marcuse (1991) chamava de "Sociedade da Opulência". Esse mascaramento do trabalho real e concreto é conveniente para a negação da singularidade do sujeito e da importância de suas atividades. Além disso, nos grupos de filiação os sujeitos são dissolvidos num todo informe, a "sociedade", que aparece como algo exterior aos indivíduos.

Por outro lado, assume-se no presente artigo que o trabalho permanece como importante na construção da identidade dos sujeitos e que ele não se resume apenas ao trabalho-mercadoria, desempenhado no interior das unidades produtivas integradas ao sistema capitalista. Entretanto, percebe-se que a relação dos sujeitos com seu trabalho é enfraquecida por ele ser fonte de sofrimento e dificilmente possibilitar espaço para o prazer real. Apesar de a atividade desempenhada não perder por completo sua capacidade de atribuir sentido à parte da vida dos sujeitos, vez que pelo menos em relação ao tempo desempenhado ela permanece relevante, o salário passa, cada vez mais, a medir o sentido das atividades desempenhadas, e as organizações buscam estabelecer laços com os sujeitos que passem pelo campo dos afetos. Estes podem funcionar como mediação entre o sujeito e seu trabalho e proporcionar vias eficientes para a descarga de pulsões vinculadas à pulsão de morte e aos instintos destrutivos do sujeito.

No capitalismo, os homens veem-se compelidos a se inserir no mercado de trabalho como mercadoria, como objeto. 0 próprio sujeito é reificado quando se submete como "coisa" e abre mão de sua autonomia. Jorge e Bastos (2009) afirmam que

[d]o ponto de vista social, o trabalho é regido pelas leis da economia e, portanto, hoje, pelo capitalismo dominante no planeta. 0 capitalismo realiza ... com grande eficácia a fantasia posta em cena por Chaplin, do homem escravizado pela máquina. 0 homem se torna um objeto.

Ao mesmo tempo, a organização passa a ser encarada como sendo capaz de agir - apesar de não ser mais que uma abstração que só adquire concretude por meio da prática dos homens. Essa prática é influenciada pelas diversas instituições sociais e pelos aparelhos de hegemonia ${ }^{5}$ - como entende Gramsci (2006a) - numa relação dialógica entre a ação sobre o real e a tomada de

\footnotetext{
5 Para Gramsci, os aparelhos de hegemonia são aquelas organizações da sociedade civil que produzem sentidos e significados e contribuem na cristalização de ideologias, tais como a igreja, a escola e os partidos políticos.
} 
consciência sobre essa ação. Os laços e as relações estabelecidos entre as pessoas no interior das empresas tendem a ficar obnubilados, como se cada indivíduo não fosse mais que um ponto de apoio para atuar em prol da organização e, que seja assim, tomado apenas como objeto. As demandas, as imposições e as violências podem ficar ocultas sob a indeterminação possibilitada pelo verniz das relações de trabalho. Essas são suportadas pela sociedade capitalista e realizadas no interior das organizações produtivas capitalistas, uma coisa sem existência própria, tornada e tomada como coisa concreta e de existência naturalizada.

Essas organizações reificadas têm grande importância na vida psíquica e social dos trabalhadores, tanto pela forma como se estabelece o relacionamento do funcionário com a empresa, quanto por causa dos investimentos libidinais que são demandados para que qualquer trabalho se realize. Há ainda no ambiente organizacional um contexto no qual, comportamentos que exacerbam o exibicionismo, a competição, o individualismo e mesmo a agressividade em busca do alcance de metas ou objetivos colocados pela direção da organização - que age sob os desígnios do sistema capitalista no qual essa se insere - contribuem para o adoecimento psíquico dos trabalhadores.

De tal maneira, sustenta-se que o ambiente das organizações produtivas pode propiciar a liberação da agressividade por meio da dominação do outro - utilizando-se da coerção moral ou física, ou das normas e regulamentos explícitos ou tácitos presentes nas organizações - ou, ainda, valendo-se da busca pelo controle sobre o ambiente exterior. Esses atributos são fruto duma dinâmica social na qual os sujeitos são constantemente colocados à prova e pela própria dinâmica do capitalismo que se sustenta na exploração do homem pelo homem.

É possível perceber que há uma permissividade que percorre o ambiente empresarial e, por um lado, uma transferência da culpa para a vítima, retratada como uma pessoa fraca, inapta para o serviço ou, de algum modo, descontente com o serviço que desempenha. Numa outra ponta, tem-se a imputação completa da culpa ao violentador, que seria anormal e teria um comportamento idiossincrático, que não seria passível de ser repetido ou que não se encaixaria num padrão específico. Para além dessas duas acepções, o que se deseja aqui é apontar para outra possibilidade de interpretação do fenômeno. Entende-se que há na sociedade atual fatores conjunturais que abrem espaço para a legitimação da satisfação de pulsões agressivas justificadas pela busca de maior produtividade. $\mathrm{Ou}$ seja: adota-se no presente artigo o entendimento de que o problema da violência e da agressividade no ambiente de trabalho é fruto de afinidades eletivas entre a conjuntura específica da sociedade contemporânea e as demandas pulsionais dos sujeitos, principalmente, na busca constante pela melhoria da performance. A transição do ser excelente para o "estar excelente" de que nos fala Freitas (2005), e que é uma manifestação do princípio de produtividade constatado por Marcuse (1978), é um bom exemplo.

Para Jorge e Bastos (2009, p. 31), na sociedade capitalista contemporânea

[a] relação entre coisas é privilegiada em detrimento da relação entre homens, dos quais são exigidos sacrifícios para o enriquecimento da civilização, ao mesmo tempo em que o produto de seu trabalho lhe é tornado inacessível. 0 objeto é posto em primeiro plano em detrimento do sujeito, tomando este por mercadoria, o que revela a primazia que aquele toma na contemporaneidade. 0 capitalismo apresenta-se, assim, como uma economia de empuxo ao gozo ${ }^{6}$ ilimitado, tornando-se uma cultura da pulsão de morte, o que se revela, por exemplo, nas toxicomanias nele onipresentes.

Assim, passam a ser tratados com naturalidade mecanismos específicos de dominação e controle que desconsideram os efeitos danosos à saúde psíquica dos indivíduos causados pela disseminação por toda a sociedade de práticas pautadas exclusivamente pela melhoria do desempenho produtivo. Assim, é no interior de uma estrutura social propícia que, muitas vezes, coloca a busca por maior

\footnotetext{
6 O termo gozo faz parte do "linguajar" lacaniano e nos seus primeiros tempos assume um sentido bastante parecido ao dado por Freud, que é o adotado no presente ensaio: o de satisfação de uma pulsão. Entretanto com o tempo abrem-se algumas diferenças no uso do termo, que merecem estudo à parte. Ver, por exemplo, Valas (2001).
}

Psicol. Argum. 2013 abr./jun., 31 (73), 319-329 
produtividade e lucratividade acima de outros fins que a violência no trabalho se banaliza e, em específico, a questão do assédio moral. Não que a violência nãotenhaacompanhadograndeparte-quiçátodaa história do trabalho. Entretanto, ela, paulatinamente, deixa de ser exercida no plano físico para se tornar mais velada, passando principalmente ao plano simbólico e chegando a se inscrever em grande parte dos códigos sociais e dos discursos que permeiam a sociedade.

\section{Considerações finais}

Crê-se que a violência no local de trabalho e também o assédio moral são problemas que estão relacionados aos processos de produção da atualidade e ao discurso da competitividade crescente do mercado onde, aparentemente, toda ação se justifica quando voltada para o objetivo maior: a lucratividade. Talvez a contemporaneidade, com a crescente dominância do comportamento calculista apontado por Weber (2004), esteja cada vez mais observando e contemporizando a violência existente, se esta se justificar enquanto meio.

É difícil de negar que cada trabalhador vivencia ao seu modo as práticas organizacionais estabelecidas. Alguns aceitando e contribuindo para a reprodução destas, outros se sujeitando a vivenciar um trabalho alienado, que pode levar ao desenvolvimento de patologias físicas e psíquicas e que podem, também, estar relacionadas umas com as outras, ou ainda se rebelando contra elas, sem que, isolados, possam fazer algo para mudar as estruturas do real. Há também que se considerar que as experiências individuais e a estrutura de personalidade de cada sujeito são fatores preponderantes no que concerne aos efeitos que a estrutura social exerce sobre cada um.

Não se pode, entretanto, deixar de lado que a sociedade exerce influência de diversas maneiras na saúde mental dos sujeitos, a começar pelo fato de a socialização se dar, basicamente, via instituições sociais (a família em primeiro lugar, depois a escola, a igreja e outras), que se alteram de sociedade para sociedade e ao longo do tempo. Assim, entende-se que a sociedade esquematiza modelos de criação de filhos que são reproduzidos e acabam por estabelecer traços genéricos que se repetem em grandes grupos de pessoas.
De toda maneira, o que se desejou salientar no presente artigo foi que, se tomada seriamente, a teoria freudiana torna a reflexão acerca da violência no ambiente de trabalho e do assédio moral mais complexa, colocando novos elementos que não podem ser desconsiderados pelos estudiosos desses assuntos. Além disso, os postulados psicanalíticos dão ensejo a se pensar na importância que a transformação ampla no modo de vida das pessoas pode ter para se resolver o problema da violência no local de trabalho. Defendese que apenas quando o homem tiver possibilidades de sublimação real em seu trabalho e em seus momentos de lazer é que será possível escapar, ainda que não completamente, dos efeitos negativos da pulsão de destruição no ambiente de trabalho e, mesmo, em outras esferas da vida dos sujeitos.

0 assédio moral aparece como exemplo de descarga agressiva da energia pulsional do sujeito. Contudo, considera-se que outras formas de violência presentes no ambiente do trabalho e mesmo na sociedade em geral, possam ser fruto da impossibilidade de sublimar a agressividade que é inerente ao ser humano, sendo essa investigação uma proposta interessante a ser pesquisada em trabalhos futuros. Ressalta-se que a proposta aqui apresentada foi de natureza teórica e exploratória. Para estudos futuros, recomenda-se que seja adotada uma pesquisa empírica, com vistas a buscar elementos que corroborem os pressupostos aqui discutidos; nesse mesmo ponto reside a limitação deste estudo.

\section{Referências}

Adorno, T., \& Horkheimer, M. (1985). Dialética do Esclarecimento: Fragmentos filosóficos. Rio de Janeiro: Jorge Zahar.

Barreto, M. S. (2000). Uma jornada de humilhações. Dissertação de Mestrado em Psicologia Social, Pontifícia Universidade Católica de São Paulo, São Paulo.

Barros, A. N., Riente, C. A., \& Guimarães, L. V. M. (2008). O lugar do trabalho na psique dos indivíduos: luto, melancolia e auto-aniquilamento do ego.XXXIIENANPAD, Rio de Janeiro.

Bicalho, R. A. (2009). Das histórias de violência em uma empresa júnior à reprodução da ideologia da administração. Dissertação de mestrado, Universidade Federal de Minas Gerais, Belo Horizonte. 
Corrêa, A. M. H, \& Carrieri, A. P. (2004). 0 assédio moral degradando as relações de trabalho: Um estudo de caso no Poder Judiciário. Revista de Administração Pública, 38(6), 1065-1084.

Dejours, C. A. (1991). Loucura do trabalho. Estudo de psicopatologia do trabalho. (4. ed.). São Paulo: Cortez-Oboré.

Enriquez, E. (2002). A organização em análise. Petrópolis: Vozes.

Freitas, M. E. (2001). Assédio sexual e moral: faces do poder perverso nas organizações. RAE-FGV, 41(2), 8-19.

Freitas, M. E. (1999). Cultura organizacional: Identidade, sedução e carisma. Rio de Janeiro: FGV.

Freitas, M. E., Heloani, J. R., \& Barreto, M. (2008). Assédio Moral no trabalho. São Paulo: Cengage Learning.

Freud, S. (1976a). Além do princípio de prazer. (Vol. XVIII 1920-1922). Rio de Janeiro: Imago. (Edição Standard Brasileira das Obras Psicológicas Completas de Sigmund Freud).

Freud, S. (1976b). Análise terminável e interminável. (Vol. XXIII 1937-1939). Rio de Janeiro: Imago. (Edição Standard Brasileira das Obras Psicológicas Completas de Sigmund Freud).

Freud, S. (1976c). Novas conferências introdutórias sobre a psicanálise. (Vol. XXII 1932-1936). Rio de Janeiro: Imago. (Edição Standard das Obras Psicológicas completas de Sigmund Freud).

Freud, S. (1976d). O mal estar na civilização. (Vol. XXI 1927-1931). Rio de Janeiro: Imago. (Edição Standard Brasileira das Obras Psicológicas Completas de Sigmund Freud).

Freud, S. (1976e). O problema econômico do masoquismo. (Vol. XIX 1923-1925). Rio de Janeiro: Imago. (Edição Standard Brasileira das Obras Psicológicas Completas de Sigmund Freud).

Freud, S. (1976f). Psicologia de grupo e análise do Ego. (Vol. XVIII 1920-1922). Rio de Janeiro: Imago. (Edição Standard Brasileira das Obras Psicológicas Completas de Sigmund Freud).

Freud, S. (1976g). O ego e o id. (Vol. XIX 1923-1925). Rio de Janeiro: Imago. (Edição Standard Brasileira das Obras Psicológicas Completas de Sigmund Freud).

Freud, A. (1990). O ego e seus mecanismos de defesa. Rio de Janeiro: Zahar.
Gramsci, A. (2006). Cadernos do cárcere. (Vol. 1). Rio de Janeiro: Civilização Brasileira, 2006a.

Hirigoyen, M.-F. (2000). Assédio moral, a violência perversa do cotidiano. Rio de Janeiro: Bertrand Brasil.

Hirigoyen, M.-F. (2002). Mal-estar no trabalho: Redefinindo assédio moral. Rio de Janeiro: Bertrand Brasil.

Horkheimer, M. (2002). Eclipse da Razão. São Paulo: Centauro.

Jorge, M. A. C., \& Bastos, F. (2009). Trabalho e capitalismo: uma visão psicanalítica. Trivium, 1(1). 21-33. Recuperado em 7 dez. 2009, de http://www.uva.br/ trivium/edicao1/artigos-tematicos/2-trabalho-e-capitalismo.pdf

Laplanche, J., \& Pontalis, J. B. (2001). Vocabulário de psicanálise. São Paulo: Martins Fontes.

Lukács, G. (2003). História e consciência de classe: Estudos sobre a dialética marxista. São Paulo: Martins Fontes, 2003.

Marcuse, H. (1978). Eros e civilização: Uma interpretação filosófica do pensamento de Freud. Rio de Janeiro: Zahar Editores, 1978.

Marcuse, H. (1991). One-dimensional man: Studies in the ideology of advanced industrial society. Londres: Routledge, 1991.

Nakasu, M. V. P. (2009). Os vestígios da pulsão de morte na formação grupal. IV Encontro internacional dos estados gerais da psicanálise. 2005. Recuperado em 19 jun. 2009, de http://www.estadosgerais.org/encontro/IV/ PT/trabalhos/Maria_Vilela_Pinto_Nakasu2.pdf

Pagès, M., Bonetti, M., Gaulejac, V., \& Descendre, D. (1987). O poder das organizações. São Paulo: Atlas.

Ruiz, E. M. (1998). Freud no divã do cárcere: Gramsci analisa a psicanálise. Campinas: Autores Associados.

Tracy, S. J., Lutgen-Sandvik, P., \& Alberts, J. K. (2006). Nightmares, demons and slaves: exploring the painful metaphors of workplace bullying. In J. Strachey (Ed.). Management communication quarterly. (Vol. 20, n. 2, pp. 148-185). London: Hogarth.

Valas, P. (2001). As dimensões do gozo. Rio de Janeiro: Jorge Zahar.

Weber, M. (2004). Economia e Sociedade: Fundamentos da sociologia compreensiva. (Vol.1). Brasília: Ed. da UnB. 